Diabetologia (1995) 38: 919-926

\title{
Islet transplantation in diabetic rats normalizes basal and exercise-induced energy metabolism
}

\author{
H. Houwing ${ }^{1}$, L. Benthem ${ }^{2}$, P.T.R. Van Suylichem ${ }^{3}$, J. Van der Leest ${ }^{2}$, J.H. Strubbe ${ }^{1}$, A. B. Steffens ${ }^{1}$ \\ ${ }^{1}$ Department of Animal Physiology, University of Groningen, Haren, The Netherlands \\ ${ }^{2}$ Department of Physiology, University of Groningen, Groningen, The Netherlands \\ ${ }^{3}$ Department of Surgery, University of Groningen, Groningen, The Netherlands
}

Summary Transplantation of islets of Langerhans in diabetic rats normalizes resting glucose and insulin levels, but it remains unclear whether islet transplantation restores resting and exercise-induced energy metabolism. Therefore, we compared energy metabolism in islet transplanted rats with energy metabolism in normal controls and in streptozotocin-induced diabetic rats. Indirect calorimetry was applied before, during, and after moderate swimming exercise. Blood was sampled by means of a heart catheter for determination of nutrient and hormone concentrations. In islet transplanted rats, the results from indirect calorimetry and the nutrient and hormone concentrations were similar to the results in normal controls. In resting diabetic rats, insulin levels were very low, while glucose levels were exaggerated. Compared to resting controls, fat oxidation and energy expenditure were elevated, but carbohydrate oxidation was similar. Exercise increased energy expenditure and was similar in diabetic and control rats. Carbohy- drate oxidation was lower and fat oxidation was higher in diabetic than in control rats. Exercise-induced increments in glucose, lactate and non-esterified fatty acid levels were the highest in diabetic rats. Thus, at rest, but not during exercise, insulin influences energy expenditure. Insulin reduces lipolysis and glycogenolysis. It enhances the relative contribution of carbohydrate oxidation and reduces fat oxidation to total energy expenditure, at rest and during exercise. Absence of insulin enhances anaerobic glycolytic pathways during exercise. It is concluded that in diabetic rats, islet transplantation of $50 \%$ of the normal pancreatic endocrine volume successfully normalizes insulin levels and hence energy metabolism at rest and during exercise. [Diabetologia (1995) 38: 919926]

Key words Islet transplantation, fuel oxidation, energy expenditure, glucose, non-esterified fatty acids, lactate, insulin.
Poorly-treated insulin-dependent diabetes mellitus is characterized by a decrease in body weight despite an enhanced food intake. This negative energy balance is not only due to an excessive loss of glucose

Received: 24 October 1994 and in revised form: 21 February 1995

Corresponding author: Dr. H.Houwing, Department of Animal Physiology, University of Groningen, P.O. Box 14, NL9750 AA Haren, The Netherlands

Abbreviations: EE, Energy expenditure; CHO-ox, carbohydrate oxidation; fat-ox, fat oxidation; $\mathrm{VO}_{2}$, oxygen consumption; $\mathrm{VCO}_{2}$, carbon dioxide production; $\mathrm{RQ}$, respiratory quotient; NEFA, non-esterified fatty acids. with urine, but also due to an increased energy expenditure (EE) at rest [1]. In addition, Nair et al. [1] reported that administration of insulin can normalize the enhancement in EE at rest. A second effect of the absence of insulin on energy metabolism is the use of energy substrates, other than glucose. Absence of insulin will lead to exaggerated plasma non-esterified fatty acid (NEFA) concentrations and according to the hypothesis of Randle et al. [2], these high NEFA levels may increase the oxidation of fat.

In the search for a treatment for diabetes considerable ttention has been paid to transplantation of islets oi Langerhans [3, 4]. Islet grafts have been transplanted in rodents to different sites and comprising 
different volumes $[5,6]$. After transplantation of islets of Langerhans into diabetic rats, resting insulin and glucose levels in blood are restored $[5,6]$. It might therefore be possible that EE is normalized. However, under conditions of daily living, including food intake, and stress or physical activity, the regulation of insulin release might not be adequate to normalize energy metabolism. In rats, oral glucose tolerance tests or meal tests have indicated that due to an absence of parasympathetic innervation, insulin release did not completely normalize glucose tolerance [5-8].

Impaired innervation of transplanted endocrine tissue may not only have its consequences for the parasympathetic control of endocrine function; $a b-$ sence of sympathetic innervation may have its consequences as well. During exercise, enhanced sympathetic activity reduces insulin secretion in rats $[9,10]$, leading to an increase in the portal venous glucagon/ insulin ratio, thus stimulating glycogenolysis and gluconeogenesis $[11,12]$. Impaired sympathetic control of endocrine pancreatic function in transplanted diabetic rats may therefore lead to impaired recruitment of hepatic glycogen, subsequently leading to an impaired carbohydrate availability for the working muscles.

The aim of this study was to determine the effects of transplantation of islet grafts equivalent to $50 \%$ of the native pancreas on energy metabolism in diabetic rats. Therefore, we compared the energy metabolism at rest and during moderate exercise in streptozotocin-induced diabetic rats with islet grafts in the portal vein, in streptozotocin-induced diabetic rats which had not received an islet graft, and in normal controls. All animals were submitted to an exercise experiment, which included swimming exercise. Indirect calorimetry was applied to assess the contribution of carbohydrate oxidation (CHO-ox) and fat oxidation (fat-ox) to energy expenditure, calculated from oxygen consumption $\left(\mathrm{VO}_{2}\right)$ and carbon dioxide production $\left(\mathrm{VCO}_{2}\right)$, under baseline conditions, during exercise and during recovery from exercise. Blood samples were drawn to determine the levels of glucose and lactate in whole blood, and NEFA and insulin in plasma.

\section{Materials and methods}

Animal care and surgery. Male inbred Albino Oxford $(\mathrm{AO} / \mathrm{G})$ rats, weight $300-380 \mathrm{~g}$, obtained from the Central Animal Laboratory of the University of Groningen were divided into three groups.

In the first group, diabetes was induced by an intravenous injection of $70 \mathrm{mg} / \mathrm{kg}$ citrate buffered streptozotocin (Zanozar, Upjohn, Kalamazoo, MI, USA) when they were in a nonfood-deprived state. This resulted in loss of body weight, glucosuria, increased water intake and blood glucose levels of more than $15 \mathrm{mmol} / 1$. Two to three weeks after diabetes induction,
$5 \mu \mathrm{l}$ isogeneic islet tissue was transplanted in the liver via the portal vein.

Islets were isolated according to the procedure described by Van Suylichem et al. [13]. Briefly, the pancreas was distended by infusing $10 \mathrm{ml}$ Krebs' Ringer solution containing $25 \mathrm{mmol} / \mathrm{l}$ HEPES and $10 \%$ bovine serum albumin into the pancreatic duct. The pancreas was then excised and cut into small pieces with a pair of scissors. A two-stage collagenase (Sigma type XI, 2200 U/mg, Sigma, St. Louis, MO, USA) digestion was performed at $37^{\circ} \mathrm{C}$ at concentrations of 1.2 and $0.7 \mathrm{mg} / \mathrm{ml}$, respectively. Islets were separated from the exocrine tissue using a discontinuous dextran gradient (Sigma industrial grade, $M_{r} 70.000$ ). Further purification of the islets was obtained by hand-picking in order to eliminate non-separated lymph nodes, vascular and ductal tissue from the islet grafts. Islets were identified with the aid of a dissection microscope (Bausch and Lomb 31-28-06) and a fluorescent lamp (Bausch and Lomb 31-33-66). With this illumination, rat islets appear as distinct ochreous bodies, whereas lymph nodes and exocrine tissue are grey. The reliability of this method has been confirmed by histology and dithizone staining.

The total islet volume was determined by measuring the islet diameters, expressed as the mean of two axes in a $5 \%$ aliquot of the islet suspension. By assuming the islets to be perfect spheres, islet volume was calculated. Grafts of $5 \mu \mathrm{l}$ endocrine tissue were prepared for transplantation by taking an appropriate portion of the total islet suspension. This volume is about $50 \%$ of the endocrine content of a normal adult pancreas. Transplantation in the liver was performed immediately after the islet isolation by direct puncture with a 23-gauge butterfly needle in the portal vein $[5,6]$.

Three to four weeks after transplantation, i. e. after recovery and regaining pre-diabetic body weight, a permanent heart catheter was inserted in a branch of the right jugular vein to sample blood in freely-moving animals [14].

A permanent heart catheter was inserted in the jugular vein in the second group and diabetes was induced 1 week later, using $70 \mathrm{mg} / \mathrm{kg}$ streptozotocin. The third group served as control group and was provided with a heart catheter. All surgery was performed under ether or halothane anaesthesia.

All animals were housed individually in perspex cages (25, 25 and $30 \mathrm{~cm})$ at room temperature $\left(21 \pm 2{ }^{\circ} \mathrm{C}\right)$ and had continuous access to food and water unless otherwise stated. The animals were maintained on a 12:12-h light-dark cycle $(07.00$ 19.00 hours lights on). The experiments were performed about 8-12 weeks after transplantation or 2-6 weeks after diabetes induction in the islet grafted group and the diabetic group, respectively. Just before the exercise experiments body weight was $330 \pm 25 \mathrm{~g}$ in the diabetic rats, $390 \pm 27 \mathrm{~g}$ in the islet transplanted rats and $401 \pm 16 \mathrm{~g}$ in the control rats.

Exercise and gas analysis. The moderate swimming exercise experiments were performed in an airtight perspex swimming pool, the upper part of which consists of a metabolic chamber filled with fresh demineralized water. The bottom of the chamber is a movable resting platform, which can be lowered into the pool, so that the rat is forced to swim in order to keeping its head in the metabolic chamber [15]. During swimming, a water flow of $0.22 \mathrm{~m} / \mathrm{s}$ was maintained. Water temperature was $32 \pm 2{ }^{\circ} \mathrm{C}$.

The airflow through the metabolic chamber was 4.5 litres/ min. $\mathrm{VO}_{2}$ and $\mathrm{VCO}_{2}$ were measured by means of an $\mathrm{O}_{2}$-analyser (Ametek S3A, Pittsburgs PA, USA) and a mass spectrometer (Balzers QMG 511, Liechtenstein), respectively, in combination with a gas flowmeter. Prior to each experiment, the measuring system was calibrated as described previously [15]. $\mathrm{EE}, \mathrm{CHO}-\mathrm{ox}$, and fat-ox were calculated according to Lusk 
[16] without taking proteins into account, since in short-term experiments and especially during swimming, collection of urine is not possible. Although this procedure introduces a small error in the absolute rates of $\mathrm{EE}, \mathrm{CHO}-\mathrm{ox}$, and fat-ox, it has proven its validity for the determination of drug-induced changes in the rates of $\mathrm{EE}, \mathrm{CHO}-\mathrm{ox}$, and fat-ox in rats under baseline conditions and during swimming [17].

Blood sampling and chemical determinations. During the experiments blood samples of $0.3 \mathrm{ml}$ were drawn, for determination of glucose and lactate levels in whole blood, and NEFA and insulin levels in plasma. After each sample, $0.3 \mathrm{ml}$ of blood from permanently cannulated, stress-free donor rats was re-infused. Between each blood sample, the tip of the catheter was filled with $7 \%$ citrate solution as an anticoagulant; citrate was used instead of heparin to avoid activation of endothelial lipase.

Blood samples were transferred into chilled $\left(0^{\circ} \mathrm{C}\right)$ centrifuge tubes containing $7 \mu \mathrm{l}$ EDTA solution $(70 \mathrm{~g} / 1)$ as anticoagulant and antioxidant. Blood glucose and lactate levels were determined by an enzymatic method using $25 \mu$ of blood $(2300$ Stat, Yellow Springs Instrument, Yellow Springs, Ohio, USA). The remaining blood was centrifuged for $12 \mathrm{~min}$ at $2600 \mathrm{~g}$ and $4^{\circ} \mathrm{C}$. The remaining plasma was stored at $-30^{\circ} \mathrm{C}$ until further handling. NEFA concentrations were measured in $25 \mu \mathrm{l}$ of plasma by an enzymatic photometric method (WAKO, Osaka, Japan). Rat-specific plasma immunoreactive insulin was determined by means of a radio-immunoassay (NOVO, Copenhagen, Denmark), guinea-pig serum M8309 serving as antiserum. Duplicate assays were performed on $25-\mu \mathrm{l}$ plasma samples. The bound and free ${ }^{125} \mathrm{I}$-labelled insulin were separated by means of a polyethylene glycol solution [18].

Experimental protocol. Food was removed about $3 \mathrm{~h}$ before the start of an experiment. After calibration of the gas analysers, the animal was placed in the metabolic chamber on top of the swimming pool [15] and connected to a polythene tube (length $400 \mathrm{~mm}$, internal diameter $1.25 \mathrm{~mm}$, outer diameter $1.75 \mathrm{~mm}$ ), which was pierced through the hood of the metabolic chamber. The experiment was started when both $\mathrm{VO}_{2}$ and respiratory quotient (RQ) had stabilized, which was attained after $1.5 \mathrm{~h}$ : At $t=0$ the platform was lowered to the bottom of the swimming pool, forcing the rat to swim. At $t=20 \mathrm{~min}$, the platform was raised to enable the rat to leave the water. After swimming, an infra-red lamp, directed at the rat, was switched on to prevent cold stress of the animal. Blood samples were taken to determine hormone and energy substrate concentrations under baseline conditions, i.e., before swimming when the animal was resting in the metabolic chamber, during exercise, and during recovery, at the time points shown in Fig. 1. To prevent emotional stress, the animals were habituated to the experimental procedure in four to five training sessions [19]. The experiments were performed between 12.00 and 16.00 hours, i.e., in the light period.

\section{Statistical analysis}

Data obtained by indirect calorimetry over 10 -min periods are expressed as mean $\pm S E M$. Data obtained for blood components are expressed as mean $\pm S E M$ for each sample point. Analysis of variance and the Mann-Whitney U-test were applied to determine differences between data obtained in the experiments of transplanted animals, diabetic animals and control animals. Wilcoxon's matched-pairs signed rank tests were used when data were compared with the baseline value. The level of significance was set at $p<0.05$.

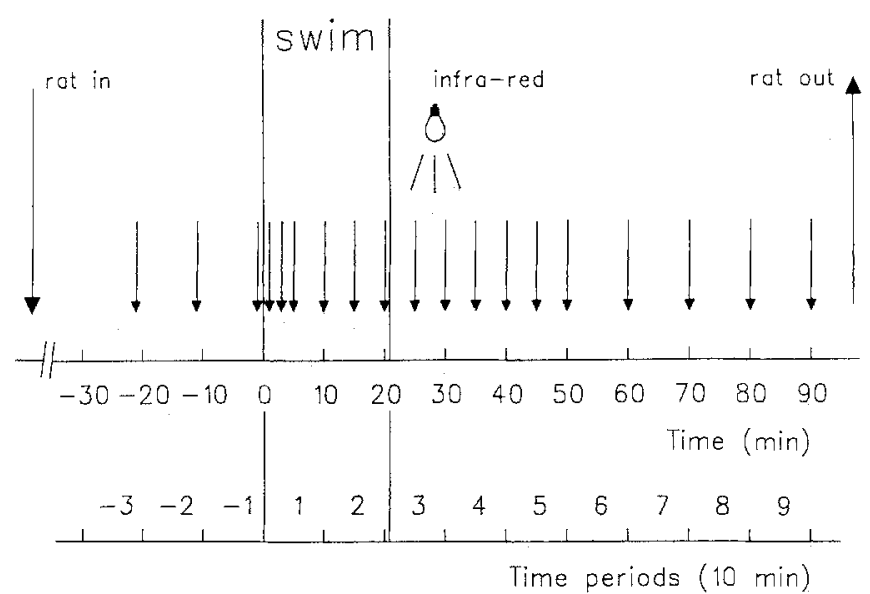

Fig. 1. Experimental design of the swimming experiment. The arrows indicate taking of blood samples [15]

Table 1. Baseline data obtained by indirect calorimetry, and of concentrations of blood glucose and lactate, plasma NEFA and insulin

\begin{tabular}{llll}
\hline & $\begin{array}{l}\text { Control } \\
n=6\end{array}$ & $\begin{array}{l}\text { Diabetes } \\
n=8\end{array}$ & $\begin{array}{l}\text { Transplants } \\
n=6\end{array}$ \\
\hline $\mathrm{VO}_{2}$ & & & \\
$\left(\mathrm{mmol}^{2} \mathrm{~kg}^{-1} \cdot \mathrm{min}^{-1}\right)$ & $0.65 \pm 0.02$ & $0.99 \pm 0.04^{\mathrm{a}}$ & $0.66 \pm 0.02$ \\
$\mathrm{VCO}_{2}$ & & & \\
$\left(\mathrm{mmol} \cdot \mathrm{kg}^{-1} \cdot \mathrm{min}^{-1}\right)$ & $0.55 \pm 0.02$ & $0.79 \pm 0.03^{\mathrm{a}}$ & $0.53 \pm 0.02$ \\
$\mathrm{RQ}$ & $0.84 \pm 0.01$ & $0.80 \pm 0.01^{\mathrm{a}}$ & $0.81 \pm 0.01^{\mathrm{a}}$ \\
$\mathrm{EE}(\mathrm{W} / \mathrm{kg})$ & $4.94 \pm 0.18$ & $7.43 \pm 0.27^{\mathrm{a}}$ & $4.98 \pm 0.15$ \\
$\mathrm{CHO}-\mathrm{ox}$ & & & \\
$\left(\mathrm{mg} \cdot \mathrm{kg}^{-1} \cdot \mathrm{min}^{-1}\right)$ & $8.1 \pm 0.9$ & $8.6 \pm 1.0$ & $6.1 \pm 0.6^{\mathrm{a}}$ \\
Fat-ox & & & \\
$\left(\mathrm{mg} \cdot \mathrm{kg}^{-1} \cdot \mathrm{min}^{-1}\right)$ & $4.0 \pm 0.3$ & $7.8 \pm 0.4^{\mathrm{a}}$ & $5.0 \pm 0.3$ \\
Glucose $(\mathrm{mmol} / \mathrm{l})$ & $4.27 \pm 0.3$ & $15.98 \pm 0.70^{\mathrm{a}}$ & $4.66 \pm 0.20$ \\
Lactate $(\mathrm{mmol} / \mathrm{l})$ & $0.56 \pm 0.07$ & $0.75 \pm 0.03$ & $0.57 \pm 0.08$ \\
NEFA $(\mathrm{mmol} / \mathrm{l})$ & $0.40 \pm 0.02$ & $0.56 \pm 0.04^{\mathrm{a}}$ & $0.45 \pm 0.05$ \\
Insulin $(\mathrm{mU} / \mathrm{l})$ & $22.4 \pm 2.6$ & $2.8 \pm 1.5^{\mathrm{a}}$ & $25.3 \pm 6.0$ \\
\hline
\end{tabular}

Values are averages $\pm S E M$ in time period $-2(-20$ to $-11 \mathrm{~min})$ for indirect calorimetry and $t=-11$ for blood samples. a significantly different from control values

\section{Results}

Basal values. Streptozotocin injection in the diabetic group resulted in extremely low plasma insulin levels $(p<0.005$; Table 1). and exaggerated basal glucose levels $(p<0.005)$, when compared to the control group. In addition, the baseline values of $\mathrm{VO}_{2}$, $\mathrm{VCO}_{2}$, fat-ox and $\mathrm{EE}$ were increased compared to control animals $(p<0.005)$, while the baseline RQ was lower. The baseline plasma NEFA levels were significantly higher in diabetic rats whereas blood lactate levels in diabetic rats were only slightly higher than in controls. In the animals with islet grafts, no differences were found in basal glucose, NEFA, insulin and lactate levels when compared to controls, 


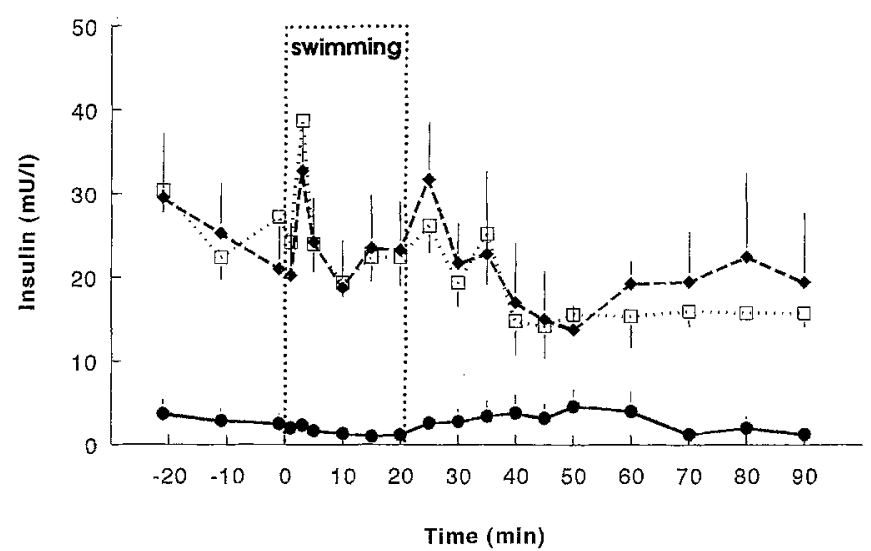

Fig.2. Concentrations of plasma insulin in the diabetic ( $)$, the transplanted $(\diamond)$ and the control $(\square)$ rats before, during and after exercise

while RQ and CHO-ox were decreased in the basal state $(p<0.05)$.

Exercise, blood and plasma concentrations. Plasma insulin levels remained extremely low in the diabetic group during the entire experiment (Fig. 2). Exerciseinduced plasma insulin levels in the rats with islet grafts followed a similar pattern to those of controls. Plasma insulin levels augmented after the onset of exercise in both the islet transplanted group and the control group, to reach maxima at $t=3$ of $38.8 \pm 4.6 \mathrm{mU} / \mathrm{l}$ and $32.8 \pm 5.1 \mathrm{mU} / \mathrm{l}$, respectively, but decreased afterwards until the end of the swimming session.

Glucose levels in the diabetic rats remained high during exercise (Fig. 3). The increment in blood glucose levels in the animals with islet grafts was not significantly different from that of control animals. In the period after exercise, blood glucose levels in the control rats and in the rats with islet grafts were similar.

Immediately after the onset of exercise blood lactate levels increased sharply, reaching maxima at $t=3 \mathrm{~min}$ of $5.76 \pm 0.45$ and $6.26 \pm 0.59 \mathrm{mmol} / \mathrm{l}$ for control rats and islet transplanted rats, respectively. The increments in exercise-induced blood lactate levels were higher in the diabetic group in which a maxim of $7.63 \pm 0.55 \mathrm{mmol} / 1$ was reached $(p<0.05)$. In the second half of the exercise experiment, blood lactate levels returned to levels only slightly higher than those under baseline conditions. Although the decrease in lactate level in the diabetic animals was similar, blood lactate levels remained higher than in controls until $t=60 \mathrm{~min}(p<0.05)$.

Plasma NEFA levels increased immediately after the onset of exercise in the control and islet transplanted group; however, the response of the group with islet grafts was slightly slower. Plasma NEFA levels were similar in the control group and the group with islet grafts in the second half of the exercise period. The exercise-induced increase of plasma

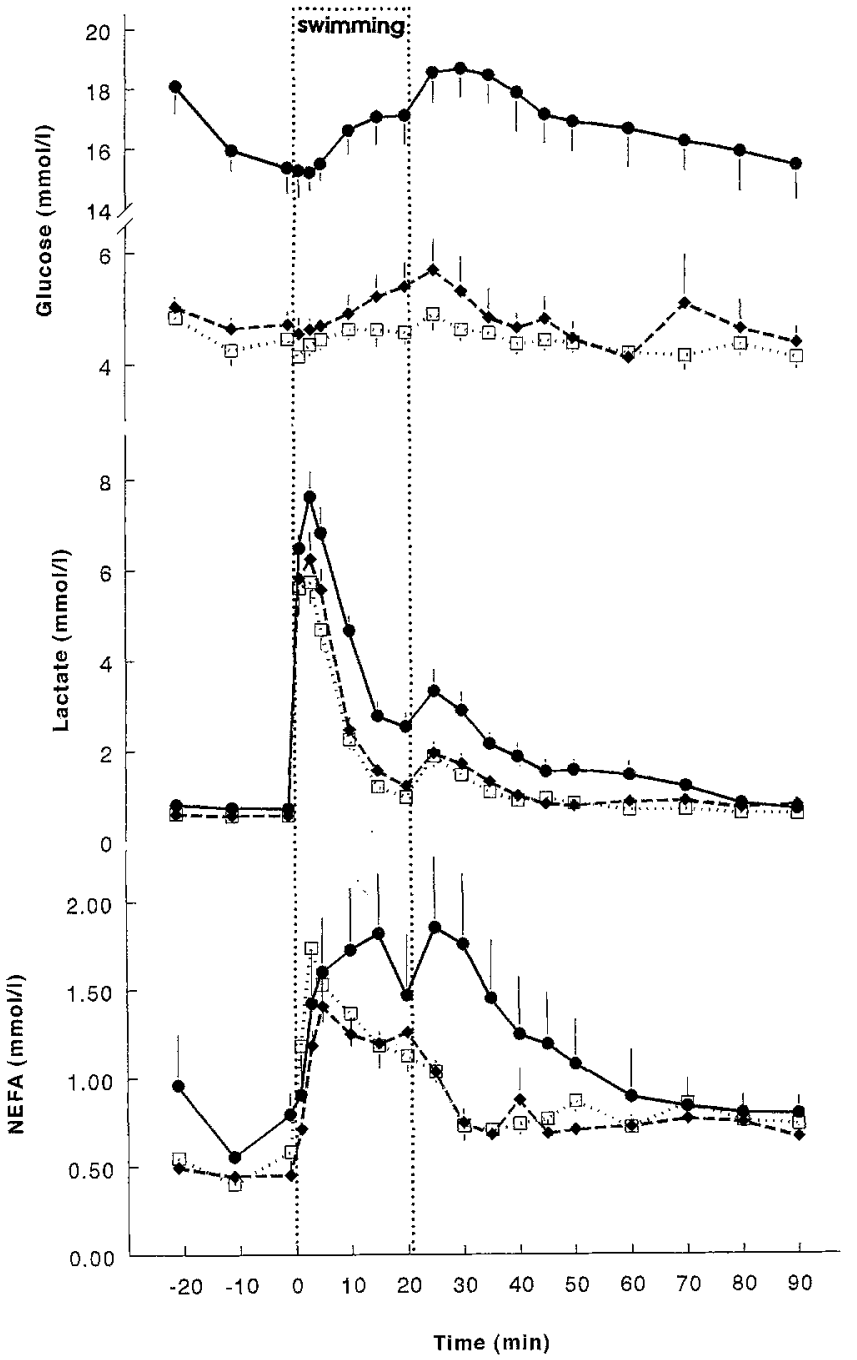

Fig. 3. Concentrations of blood glucose and lactate, and plasma NEFA in the diabetic $(\bullet)$, the transplanted $(\bullet)$ and the control ( $\square$ ) rats before, during and after exercise

NEFA levels in the diabetic group was higher, but not significantly different from controls. Plasma NEFA levels remained higher in the diabetic group $(t=30 \mathrm{~min}: 1.76 \pm 0.40 \mathrm{mmol} / \mathrm{l})$ than in the control group ( $t=30 \mathrm{~min}: 0.73 \pm 0.08 \mathrm{mmol} / \mathrm{l} ; p<0.05) \mathrm{dur}-$ ing the first $15 \mathrm{~min}$ of the period after swimming.

Exercise, indirect calorimetry. $\mathrm{VO}_{2}, \mathrm{VCO}_{2}$ and $\mathrm{RQ}$ increased in the first half of the swimming period in all the groups (Fig.4). $\mathrm{VO}_{2}$ and $\mathrm{VCO}_{2}$ were still augmented in the second half of the swimming period, while RQ returned to basal levels in the control group, but decreased under basal levels in the diabetic group $(0.76 \pm 0.01 ; p<0.05)$. $\mathrm{VO}_{2}$ and $\mathrm{VCO}_{2}$ were higher (at the time periods $4-8$ ), while RQ was lower (time periods 4 and 5) in the diabetic group than in controls and islet grafted rats after the swimming session. The $\mathrm{VO}_{2}, \mathrm{VCO}_{2}$, and $\mathrm{RQ}$ patterns were similar to those of control animals in the animals with islet grafts. 


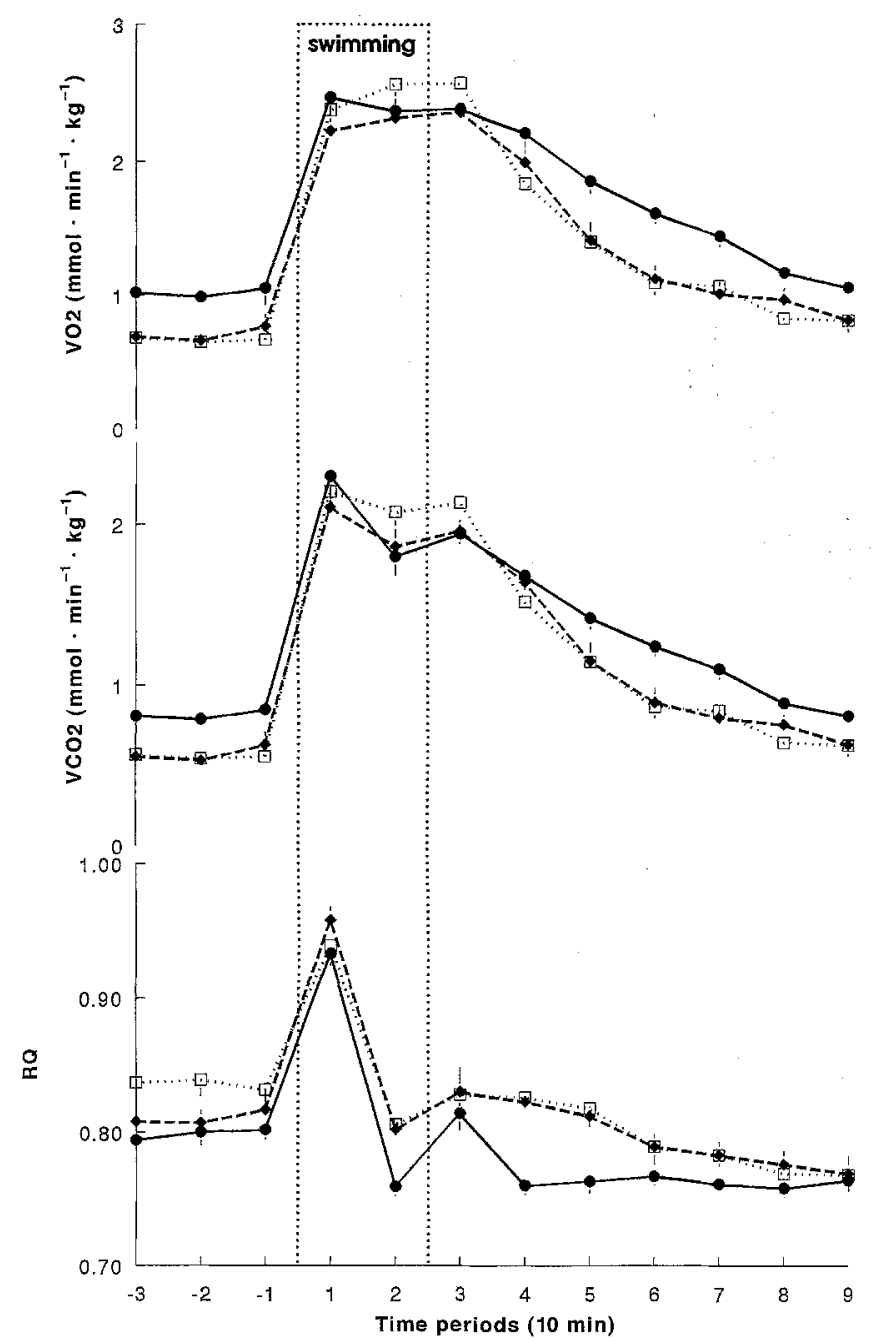

Fig.4. Results of indirect calorimetry: oxygen consumption $\left(\mathrm{VO}_{2}\right)$, carbon dioxide production $\left(\mathrm{VCO}_{2}\right)$ and respiratory quotient $(\mathrm{RQ})$ in the diabetic $(\bullet)$, the transplanted $(\bullet)$ and the control $(\square)$ rats before, during and after exercise

CHO-ox also increased in the first half of the swimming period (Fig. 5) and remained higher than during rest in the second half of exercise in both the control and islet grafted animals. However, CHO-ox returned $(p<0.005)$ to almost basal values in the diabetic animals. CHO-ox initially increased after swimming, in particular in the diabetic animals, but in these animals $\mathrm{CHO}-$ ox returned to levels below those of the control as well as of the transplanted group at the time periods 4 and $5(p<0.05)$. CHOox was similar in all groups 30 min after swimming.

Fat-ox was higher during exercise in the diabetic animals than in the controls $(22.39 \pm 0.88$ vs $19.47 \pm$ $0.68 \mathrm{mg} \cdot \mathrm{kg}^{-1} \cdot \mathrm{min}^{-1} ; p<0.05$ ), but increments from basal values were similar in both groups. Fat-ox decreased in the diabetic animals in the first 5 min after swimming. Subsequently fat-ox increased again in the diabetic animals and remained higher than in control animals during $50 \mathrm{~min}(p<0.005)$. Although fat-ox in the transplanted animals was slightly higher than

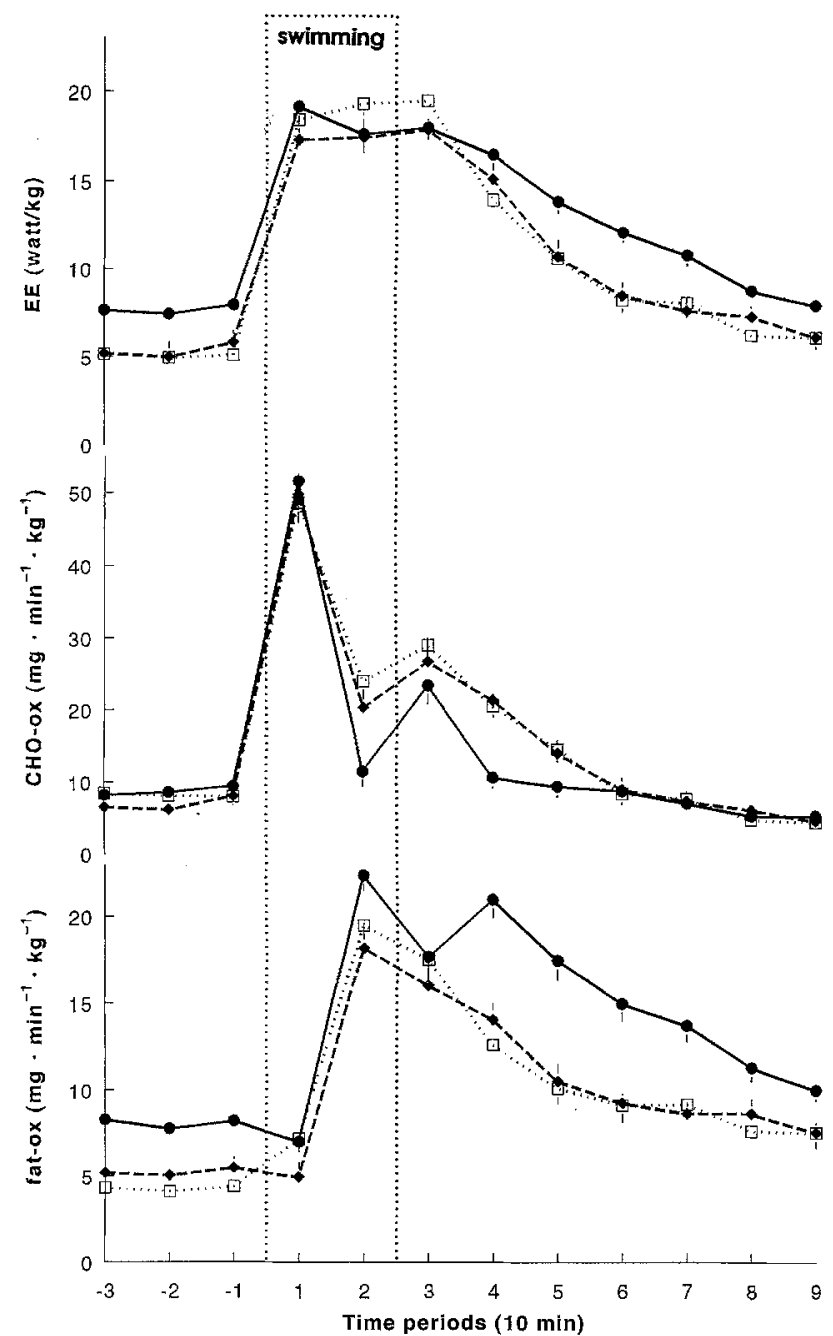

Fig.5. Results of indirect calorimetry: energy expenditure (EE), carbohydrate oxidation (CHO-ox) and fat oxidation (fat-ox) in the diabetic $(\bullet)$, the transplanted $(\bullet)$ and the control $(\square)$ rats before, during and after exercise

in control animals in the basal state, there were no. marked differences during or after exercise.

The increased basal fat-ox in the diabetic rats was accompanied by an increased EE compared to controls. During the exercise period and the early recovery period, EE was almost identical in the diabetic and in the control animals. However, EE was higher in the diabetic animals than in the control animals $(p<0.05)$ in the period after swimming $(t=30 \mathrm{~min}$ until $t=80 \mathrm{~min}$ ) and returned to basal levels.

\section{Discussion}

The results from this study indicate a deterioration of energy metabolism in diabetic rats at rest as well as during exercise, which was normalized after transplantation of pancreatic islets.

Baseline energy metabolism was characterized by an excessive increase in $\mathrm{EE}$ when expressed as $\mathrm{W} / \mathrm{kg}$. 
One might argue that the diabetic animals had a significant by lower body weight, representing a relatively higher lean body mass than the control and the transplanted group. However, when EE is expressed as W/kg $/ \mathrm{kg}^{0.75}\left(5.88 \pm 0.29 \mathrm{~W} / \mathrm{kg}^{0.75}\right.$ in diabetic animals vs $3.26 \pm 0.21 \mathrm{~W} / \mathrm{kg}^{0.75}$ in control animals), the observed increase in EE still stands. Therefore, the measured increase in $\mathrm{EE}$ is the result of a true increase in metabolic rate instead of a scaling effect caused by the loss of body mass in the diabetic animals. Since diabetic rats have a reduced fat content and concomitantly a reduced thermo-insulation, it is very probable that the higher resting $\mathrm{EE}$ is needed to maintain body temperature.

In insulin-dependent diabetes, the insulin deficiency results in high glucose levels and consequently in a disturbed carbohydrate metabolism. The Cori cycle [20], i. e. glucose metabolized to lactate, followed by gluconeogenesis in the liver, will show an increased turnover rate [21, 22]. This increased cycling rate involves a negative ATP balance and is a second factor contributing to increase EE. The excess in EE, as observed in the diabetic rats, is comparable with reports for lean, poorly-controlled insulin-dependent diabetic humans [1]. In these patients, insulin administration reduced the increased resting EE [1], indicating that under baseline conditions $\mathrm{EE}$ is dependent on the presence of insulin.

The increased baseline $\mathrm{EE}$ in diabetic rats was characterized by an enhanced fat-ox, whereas CHOox was not different from controls. The low plasma insulin levels caused higher plasma NEFA levels, due to a decreased lipogenesis, shifting the relative contribution in EE towards fat-ox $[2,23]$. In experiments in non-diabetic resting humans in which a hyperinsulinaemic euglycaemic clamp was performed, the NEFA levels and fat-ox decreased, whereas $\mathrm{CHO}-\mathrm{ox}$ was not influenced, indicating a shift towards a relatively higher $\mathrm{CHO}-o x$. Total glucose disappearance increased in the meantime as the result of an increased glycogen deposition [24]. Leg indirect calorimetry, used to determine skeletal muscle metabolism in a similar hyperinsulinaemic euglycaemic clamp study, also revealed a suppression of fatox and an increase in CHO-ox [25]. Insulin injections $(8 \Pi U / \mathrm{kg})$ in rats decreased glucose levels and increased RQ, indicating a diminished fat-ox [26]. Preventing a decrease in NEFA levels during an insulin clamp by means of an exogenous triglyceride infusion, reduced carbohydrate oxidation by $60 \%$ in resting subjects [27]. These results indicate that under basal conditions, insulin influences the relative contribution of carbohydrates and fat to total EE more by regulation of the concentration of circulating NEFA than by its regulatory effect on blood glucose.

In the first half of the exercise period, EE was augmented in all three experimental groups. However, this period does not reflect steady-state conditions, probably due to the occurrence of feedforward stimulation of respiration $[15,28]$. In the second half of the exercise period, no difference in EE was observed between the diabetic and the control animals. This suggests that during exercise, diabetic animals use less extra energy above basal EE than do control animals. Under basal conditions energy is consumed to maintain basic body functions and body temperature. During exercise, on the other hand, energy turnover rate is predominantly determined by the level of physical exercise. The heat produced by the working muscles will exceed the amount of heat necessary for maintenance of body temperature. Although the intensity of physical activity was not measured, it can be expected that the exercise strength was identical in all animals. Hence, it is not surprising that the absolute level of EE during swimming in the diabetic animals did not differ from that in control animals. This means that, while EE under baseline conditions appears to be strongly influenced by the presence of insulin, muscle EE during exercise is independent of insulin.

Furthermore during exercise, and certainly during recovery, the absence of insulin in the diabetic animals resulted in an enhanced contribution of fat-ox to total EE which was even more prominent than in the basal state. This might be due to the higher plasma NEFA concentrations observed in the diabetic animals during exercise. The relative contribution of $\mathrm{CHO}-\mathrm{ox}$ to EE during exercise was not only different when compared to the basal state, but also much lower than in controls. The regulatory effect of insulin on fuel oxidation during exercise was further shown in experiments in which insulin was administered to exercising humans; $\mathrm{CHO}-0 x$ was increased compared to exercising humans not receiving insulin [29], while both non-esterified fatty acid levels and fat-ox were decreased [24]. During exercise in pancreatectomized dogs, thus in total absence of insulin, inhibition of fat-ox with methylpalmoxirate and inhibition of lipolysis with the $\beta$-blocker propranolol resulted in an increased whole body glucose uptake [30]. This means again that also during exercise, the exaggerated NEFA concentrations, caused by the absence of insulin, is a determining factor in the regulation of carbohydrate metabolism.

The lactate concentrations in blood increased in the first minute of exercise in all groups, indicating a non-sufficient oxygen supply. The origin of the increased lactate concentration in blood is, at least partly, caused by an increased production in muscle groups by stimulation of $\beta_{2}$-adrenoceptors by adrenaline $[9,31]$. The anaerobic glycolysis, a part of carbohydrate metabolism, was enhanced in the diabetic animals, since lactate levels were higher. However, as glycogen storage in muscles is reduced in diabetic animals [9], glucose is probably provided by uptake from the blood. Basal glucose uptake in diabetic muscle cells is reported to be lower than in non-diabetic 
muscle cells [32]. The higher lactate increments in the diabetic rats $[22,33,34]$ suggest that glucose transport into the exercising muscles is normal [35]. When high levels of lactate are available, as in the diabetic rats, hepatic lactate uptake [36] and gluconeogenesis are increased [20]. The higher hepatic lactate uptake, the higher gluconeogenesis and also the reduced CHO-ox will be responsible for the high and increasing glucose levels. This means that, although in baseline conditions glucose uptake in muscle cells is disturbed, glucose uptake during exercise is enhanced leading to an increased anaerobic glycolysis.

Transplantation of $50 \%$ of the normal pancreatic endocrine volume in diabetic rats results in a normalization of the disturbed resting and exercise-induced energy metabolism in the diabetic rats, as shown by almost normal CHO-ox, fat-ox and EE. Whereas increased triglyceride levels were reported in diabetic rats provided with intrahepatic beta cells [37], NEFA levels in plasma as well as glucose and lactate levels in blood completely returned to normal values. In our exercise experiments, we expected that the plasma insulin levels would decrease in the control animals during exercise, since this has been reported in Wistar rats under similar conditions of exercise intensity and duration $[10,15,19]$. However, the decrease was not clear, which might be caused by the use of another strain of rats. Nevertheless, the insulin levels remained almost identical in the transplanted and the control group. This is in contrast to the increasing insulin levels after islet cell autotransplantation in pancreatectomized dogs performing longterm treadmill exercise. In these animals glucose levels remained similar to those in control dogs [38]. Portis et al. [38] suggested a loss of neural control after transplantation. In rats, however, anatomical evidence of sympathetic reinnervation of intraportal islet grafts has been reported [39]. Whether reinnervation is responsible for the similar concentrations of plasma insulin in our data remains unclear and is now under investigation. Anatomical evidence of parasympathetic reinnervation of transplanted islets was found in mice as well [40]. However, the functional importance of parasympathetic reinnervation remains unclear, since transplantation of $100 \%$ of the total pancreatic endocrine volume was not sufficient to restore glucose tolerance [6]. In that study, the absence of a functional parasympathetic innervation or a reduced insulin secreting capacity of the transplanted islets might be responsible for the impaired glucose tolerance. Unpublished histological examinations showed that most observed islets were viable, but some of them might have been lost due to the transplantation procedure [6]. From the present results, however, it is not clear whether only the presence of insulin or also the physiological regulation of insulin release during exercise is important in the normalization of energy metabolism. If autonomic ner- vous innervation plays an important role in the physiological regulation of insulin release, the transplanted islets in this study could be reinnervated.

From the results in this study, it is concluded that 1) under baseline conditions the presence of insulin influences $\mathrm{EE}$, but not during exercise 2) insulin enhances the relative contribution of $\mathrm{CHO}$-ox to the $\mathrm{EE}$, by means of the reduction of lipolysis, glycogenolysis and fat-ox, under baseline conditions as well as during exercise 3) absence of insulin also enhances anaerobic glycolytic pathways during exercise 4) islet transplantation of $50 \%$ of the normal pancreatic volume successfully normalizes insulin levels and thereby energy metabolism in diabetic rats at rest as well as during exercise.

Acknowledgements. This study was supported by a grant from the Netherlands Diabetes Foundation. The authors want to thank Mr. J. E. Bruggink and Ms. W. Meeuwsen for analysis of the blood samples.

\section{References}

1. Nair KS, Halliday D, Garrow JS (1984) Increased energy expenditure in poorly controlled type I (insulin-dependent) diabetic patients. Diabetologia 27: 13-16

2. Randle PJ, Garland PB, Hales CN, Newsholme EA (1963) The glucose fatty-acid cycle. Its role in insulin sensitivity and the metabolic disturbances of diabetes mellitus. Lancet I:785-789

3. Gray DWR, Morris PJ (1987) Developments in isolated pancreatic islet transplantation. Transplantation 43: 321331

4. Federlin KF (1993) Islet transplantation. The connection of experiment and clinic exemplified by the transplantation of islets of Langerhans. Exp Clin Endocrinol 101: 334-345

5. Van Suylichem PTR, Strubbe JH, Houwing H, Wolters GHJ, Van Schilfgaarde R (1992) Insulin secretion by rat islet isografts of a defined endocrine volumè after transplantation to three different sites. Diabetologia 35: 917-923

6. Van Suylichem PTR, Strubbe JH, Houwing H, Wolters GHJ, Van Schilfgaarde R (1994) Rat islet isograft function: effect of graft volume and transplantation site. Transplantation 57: 1010-1017

7. Strubbe JH, Van Wachem P (1981) Insulin secretion by the transplanted neonatal pancreas during food intake in fasted and fed rats. Diabetologia 20: 228-236

8. Trimble ER, Berthoud HR, Siegel EG, Jeanrenaud B, Renold AE (1981) Importance of cholinergic innervation of the pancreas for glucose tolerance in the rat. Am J Physiol 241:E337-E341

9. Galbo H (1983) Hormonal and metabolic adaptation to exercise. Thieme, Stuttgart

10. Scheurink AJW, Steffens AB, Bouritius H et al. (1989) Sympathoadrenal influence on glucose, FFA, and insulin levels in exercising rats. Am J Physiol 256:R161-R168

11. Miles PDG, Finegood DT, Lickley HLA, Vranic M (1992) Regulation of glucose turnover at the onset of exercise in the dog. J Appl Physiol 72: 2487-2494

12. Wasserman DH, Williams PE, Lacy DB, Goldstein RE, Cherrington AD (1989) Exercise-induced fall in insulin and hepatic carbohydrate metabolism during muscular work. Am J Physiol 256:E500-E509 
13. Van Suylichem PTR, Wolters GHJ, Van Schilfgaarde R (1990) The efficacy of density gradients for islet purification: a comparison of seven density gradients. Transplant Int 3: $156-161$

14. Steffens AB (1969) A method for frequent sampling of blood and continuous infusion of fluids in the rat without disturbing the animal. Physiol Behav 4: 833-836

15. Benthem L, Bolhuis JW, Van der Leest J, Steffens AB, Zock JP, Zijlstra WG (1994) Methods for measurement of energy expenditure and substrate concentrations in swimming rats. Physiol Behav 56: 151-159

16. Lusk G (1924) The elements of the science of nutrition, 4th edn. Johnson Reprint Corp, New York

17. Benthem L, Scheurink AJW, Van der Leest J, Leuvenink H, Zijlstra WG, Steffens AB (1993) Effects of long-term d-fenfluramine treatment on energy metabolism in rats. Eur J Pharmacol 232: 279-286

18. Henquin JC, Malvaux P, Lambert AE (1974) Glucagon immunoassay using polyethylene glycol to precipitate antibody-bound hormone. Diabetologia 10: 61-68

19. Scheurink AJW, Steffens AB, Dreteler G, Benthem L, Bruntink R (1989) Experience effects exercise-induced changes in catecholamines, glucose and FFA. Am J Physiol 256:R169-R173

20. Cori CF, Cori GT (1929) Glycogen formation in the liver from $D^{-}$and L-lactic acid. J Biol Chem 51: 389-403

21. Sestoft L, Trap-Jensen J, Lyngsøe J et al. (1977) Regulation of gluconeogenesis and ketogenesis during rest and exercise in diabetic subjects and normal men. Clin Sci Mol Med 53: 411-418

22. Wahren J (1979) Glucose turnover during exercise in healthy man and in patients with diabetes mellitus. Diabetes 28[Suppl. 1]:82-88

23. Jansson E (1980) Diet and muscle metabolism in man. Acta Physiol Scand., [Suppl487]:1-24

24. Wasserman DH, Geer RJ, Rice DE et al. (1991) Interaction of exercise and insulin action in humans. Am $\mathbf{J}$ Physiol 260:E37-E45

25. Kelley DE, Reilly JP, Veneman T, Mandarino LJ (1990) Effects of insulin on skeletal muscle glucose storage, oxidation, and glycolysis in humans. Am J Physiol 258:E923E929

26. Menendez JA, Atrens DM (1989) Insulin increases energy expenditure and respiratory quotient in the rat. Pharmacol Biochem Behav 34: 765-768

27. Thiébaud D, DeFronzo RA, Jacot E et al. (1982) Effect of long chain triglyceride infusion on glucose metabolism in man. Metab Clin Exp 31: 1128-1136
28. Sonne B (1991) Involvement of feedforward stimulation in cardiorespiratory and metabolic control during exercise. Clin Physiol 11: 399-410

29. Devlin JT, Barlow J, Horton ES (1989) Whole body and regional fuel metabolism during early postexercise recovery. Am J Physiol 256:E167-E172

30. Yamatani K, Shi ZQ, Giacca A et al. (1992) Role of FFAglucose cycle in glucoregulation during exercise in total $a b-$ sence of insulin. Am J Physiol 263:E646-E653

31. Stainsby WN, Brechue WF, O'Drobinak DM (1991) Regulation of muscle lactate production. Med Sci Sports Exerc 23: 907-911

32. Klip A, Marette A, Dimitrakoudis D et al. (1992) Effect of diabetes on glucoregulation. From glucose transporters to glucose metabolism in vivo. Diabetes Care 15[Suppl 4]:1747-1766

33. Challis RAJ, Vranic M, Radda GK (1989) Bioenergetic changes during contraction and recovery in diabetic rat skeletal muscle. Am J Physiol 256:E129-E137

34. Vranic M, Wasserman D, Bukowiecki L (1990) Metabolic implications of exercise and physical fitness in physiology and diabetes. In: Rifkin H, Porte D (eds) Diabetes mellitus, theory and practice. Elsevier Science Publishers New York, Amsterdam London, pp 198-219

35. Wahren J, Hagenfeldt L, Felig P (1975) Splachnic and leg exchange of glucose, amino acids, and free fatty acids during exercise in diabetes mellitus. J Clin Invest 55: 13031314

36. Wasserman DH, Connolly CC, Pagliassotti MJ (1991) Regulation of hepatic lactate balance during exercise. Med Sci Sports Exerc 23: 912-919

37. Keymeulen B, Teng H, Vetri M, Gorus F, In 't Veld P, Pipeleers DG (1992) Effect of donor islet mass on metabolic normalization in streptozotocin-diabetic rats. Diabetologia 35: 719-724

38. Portis AJ, Warnock GL, Finegood DT, Belcastro AN, Rajotte RV (1990) Glucoregulatory response to moderate exercise in long-term islet cell autografted dogs. Can J Physiol Pharmacol 68: 1308-1312

39. Griffith RC, Scharp DW, Hartman BK, Ballinger WF, Lacy PE (1977) A morphological study of intrahepatic portalvein islet isografts. Diabetes 26: 201-214

40. Korsgren O, Jansson L, Andersson A, Sundler F (1993) Reinnervation of transplanted pancreatic islets. A comparison among islets transplanted into the kidney, spleen and liver. Transplantation 56: 138-143 